\title{
Who Gets to Lead the Multinational Team? An Updated Status Characteristics Perspective
}

\author{
Paunova, Minna
}

Document Version

Accepted author manuscript

Published in:

Human Relations

DOI:

$10.1177 / 0018726716678469$

Publication date:

2017

License

Unspecified

Citation for published version (APA):

Paunova, M. (2017). Who Gets to Lead the Multinational Team? An Updated Status Characteristics Perspective. Human Relations, 70(7), 883-907. https://doi.org/10.1177/0018726716678469

Link to publication in CBS Research Portal

\section{General rights}

Copyright and moral rights for the publications made accessible in the public portal are retained by the authors and/or other copyright owners and it is a condition of accessing publications that users recognise and abide by the legal requirements associated with these rights.

Take down policy

If you believe that this document breaches copyright please contact us (research.lib@cbs.dk) providing details, and we will remove access to the work immediately and investigate your claim. 


\section{Who Gets to Lead the Multinational Team?: An Updated Status Characteristics Perspective Minna Paunova}

Journal article (Post print version)

CITE: Who Gets to Lead the Multinational Team? : An Updated Status Characteristics Perspective. / Paunova, Minna. In: Human Relations, Vol. 70, No. 7, 07.2017, p. 883-907.

Copyright () २०16 The Author. Reprinted by permission of SAGE Publications.

DOI: $10.1177 / 0018726716678469$

Uploaded to Research@CBS: July २०17 
NOTE: This is an unedited, uncorrected copy of an article published in Human Relations. Please refer to the printed version:

Paunova, M. (2016). Who gets to lead the multinational team? An updated status characteristics perspective. Human Relations. Published online before print November 22, 2016, doi:

$10.1177 / 0018726716678469$.

Who gets to lead the multinational team? An updated status characteristics perspective

\author{
Minna Paunova \\ Copenhagen Business School \\ Dalgas Have 15 \\ Frederiksberg 2000 \\ Denmark \\ T: +4552220832 \\ mp.ibc@cbs.dk
}




\title{
Who gets to lead the multinational team? An updated status characteristics perspective
}

\begin{abstract}
This paper examines the emergence of informal leadership in multinational teams. Building on and extending status characteristics theory, the paper proposes and tests a model that describes how global inequalities reproduce in multinational teams, and accounts for who gets to lead these teams. It is argued that an individual's language (i.e., a specific status characteristic) and nationality (i.e., a diffuse status characteristic) predict deference received from peers (i.e., leadership status). However, individuals enhance and/or compensate for the effects of their status characteristics by virtue of their core self-evaluations. A study of over 230 individuals from 46 nationalities working in 36 self-managing teams generally supports the expected main and moderation effects. Individual core self-evaluations enhance an otherwise weak effect of English proficiency, but compensate for low levels of national development. The paper concludes with implications for practice, and linking micro- and macro-level theories of status and global inequality.
\end{abstract}

\section{Keywords}

core self-evaluation, English proficiency, language, leadership emergence, leadership perception, leadership status, multinational teams, national development, nationality, status characteristics 


\section{Introduction}

The global societal order appears stratified into macro-level national and linguistic power structures (Bourdieu, 2005; Meyer et al., 1997; Phillipson, 1992; 2009; Wallerstein, 1974). Societal inequality reproduces in formal and informal organizational hierarchies (Magee and Galinsky, 2008; Ridgeway, 2004). Yet, little is known about whether and how global inequality reproduces in multinational teams and organizations (Riaz, 2015). In multinational teams, nationality and language might shape the deference received and the influence people have as team leaders, and individual members might change or fail to change this. Intuition from status characteristics research can be brought to the transnational domain to examine who gets to lead originally leaderless (i.e., self-managing) teams comprised of members with diverse national and linguistic backgrounds. Status characteristics theory explains the rapid emergence and reproduction of social inequality in leadership and other interpersonal status hierarchies (Levine and Moreland, 1998; Magee and Galinsky, 2008), suggesting that status characteristics, defined as observable and socially significant characteristics of group members that carry beliefs about "who's got it and who hasn't" as a potential leader of a group (Ridgeway, 2001: 642), are central to understanding how leadership roles are assigned and maintained (Berger et al., 1974; Correll and Ridgeway, 2003). In teams and other groups with a collective task orientation, pressure to perform a task well creates expectations about which individuals will make more valuable contributions to the collective task. Individuals expected to do so, based on status characteristics such as-we argue - nationality and language, are given more opportunities to contribute (e.g., speak more often). Self-fulfilling prophecies then produce observable differences in informal leadership status, defined as the position in the social hierarchy that results from accumulated acts of follower deference (Ridgeway, 2001). 
Despite contributions of status characteristics theory to the study of informal leadership status in teams, several limitations of the theory and its applications exist. The theory does not directly delimit status characteristics that are socially significant (Gray and Kish-Gephart, 2013). Instead, insights on macro-level inequality are needed to inform theorizing about status in groups. This might partially explain why the theory has rarely been applied outside of domestic settings, and has not been shown to generalize transnationally (cf. Haas, 2005). Although most scholars focus on characteristics such as gender and race in North American contexts, and assume these to have broad social significance, social categories relevant in one society are not necessarily relevant worldwide. Racial labels, for example, are notoriously arbitrary, so the meaning of black is highly variable across time and national contexts (Cohen and Kennedy, 2013; Roediger, 2002). Meanwhile, nationality and language are globally significant characteristics, with real repercussions to the status dynamics of multinational teams. Research in international studies such as world society and global field theories (Go, 2008; Meyer et al., 1997) allow us to develop this argument.

Status characteristics research also focuses nearly exclusively on observable, easily quantifiable, and "objective" biographical and demographic traits (Paunova, 2015). Innate traits and temporary psychological states, other than the performance expectations of others, are not usually conceived to influence status in newly formed groups, implying an almost automatic replication of macro-level structures, leaving limited room for individual agency and change within small groups, and neglecting the empirical reality (Anderson and Kilduff, 2009). Concepts of the self (e.g., self-image, self-views, self-evaluations, etc.) are overlooked within the context of empirical status research (Della Fave, 1980), but they play a role in (re)producing societal stratification (Bourdieu, 1984), and matter to how others perceive and evaluate the self as a leader of teams (Judge et al., 2002). We theorize and test whether the 
fundamental premises that individuals hold about themselves and their functioning in the world (i.e., core self-evaluations) tie into the formation of leadership hierarchies in teams.

This study contributes to status characteristics research in two ways. First, status characteristics theory emphasizes a perceiver-centric perspective, so emergent hierarchies in groups are a function of how members perceive each other. We complement this approach with an actor-centric perspective that emphasizes psychological processes behind hierarchy formation, that is, actors' own agentic motives (i.e., core self-evaluation) (Magee et al., 2016). Second, we advance the literature by extending the set of characteristics relevant to status. There has been a pressing need to do so because language and nationality are two attributes of increasing relevance as teams and organizations grow more global. Relatedly, we develop a micro-level model of nationality as a basis for global inequality, thereby extending the scope of arbitrary-set categories normally examined in social psychological studies of inequality such as race and social class (Sidanius et al., 2004).

More broadly, we contribute to research on multinational team diversity by addressing status processes. First, we highlight that national differences, more than simply markers of differences in values and worldviews, are inherently hierarchical. In most international management research, nationality is assumed to carry no status (Earley, 1999; Jonsen et al., 2011); it is simply a parameter that separates individuals, groups, and organizations horizontally, rather than vertically, producing ingroup-outgroup antagonism and failures during collaboration (Behfar et al., 2006; Haas and Cummings, 2014; Hinds et al., 2013; Tenzer et al., 2013). We show that nationality also produces vertical differences and disparity in teams (Harrison and Klein, 2007). Second, we not only replicate but add to studies of linguistic diversity and team processes (Neeley et al., 2012; Neeley, 2013) by demonstrating the role of agency in molding these processes. Finally, by showing that one's self-evaluations 
factor into the overall evaluative processes in teams, we enhance the research base on the relationship between inequality and agentic behavior (Magee et al., 2016).

In summary, we use an updated status characteristics perspective to assess who gets to lead the multinational team. We consider a set of status characteristics in light of (1) the global societal order (i.e., zooming in on nationality and language), thereby extending application of status characteristics theory to the increasingly more significant domain of multinational work settings, and (2) individual self-concepts, thereby complementing the perceiver-centric perspective of the theory with an agentic, actor-centric perspective. We detail these considerations below, and explain how we test hypotheses that relate nationality, language, and core self-evaluations with leadership status. Results suggest that macro-level national and linguistic power structures reproduce at the micro level, but only under some conditions. Drawing on their core self-evaluations to signal their worth as leaders to others, individuals contribute to making or breaking latent hierarchies. To inform research and practice, we discuss these micro-level findings, and how team leadership hierarchies might reinforce or change the macro-level, global order in turn.

\section{Theory and hypotheses}

Who gets to lead originally leaderless teams, and why, has been a topic of much research (Anderson and Brown, 2010; Paunova, 2015). Status characteristics theory and its companion, expectation states theory, suggest that observable and socially significant characteristics form the basis of self-fulfilling prophecies, which explain how leadership roles are assigned and maintained. These status cues, which fuel beliefs and expectations about individuals' worth as potential leaders of teams, generally come in two varieties: specific and diffuse. Specific status characteristics reflect ability and/or expertise pertinent to a group task such as education, training, certification, etc. Meanwhile, diffuse status characteristics such as 
race, gender, social class, etc. reflect general beliefs about the desirability of certain traits and social categories, and diffuse through a variety of settings in which they have no obvious relevance (Correll and Ridgeway, 2003). Both diffuse and specific status characteristics carry a burden of proof outside of domains in which they are relevant (Webster, 1977). Just like gender and race, education and certification must not be task- or domain-relevant to matter (Ridgeway and Fisk, 2012).

In newly formed groups, only a few status characteristics are usually observable (i.e., known). Individuals generalize from what is known, assuming that a person's unknown characteristics accord with known ones (Della Fave, 1980). Since once performance expectations are in place, a self-fulfilling mechanism cements the status hierarchy, who gets to lead depends almost entirely on one's immediately observable status characteristics (Driskell and Mullen, 1990; Magee and Galinsky, 2008). In uncommon scenarios in which actors are initially undifferentiated by status characteristics, expectations form through interactions over time during evaluations of specific performance episodes. Truly homogenous groups are theoretically interesting, but groups in which members are differentiated by some status characteristic are more common in the real world (Friedkin and Johnsen, 2003). In these groups, expectations form immediately on first meeting, without observation of performance, and hierarchies develop quickly, sometimes in a matter of minutes (Barchas and Fisek, 1984; Webster, 1977). Although it is unlikely that people merit status in so little time, once a status system develops, it might never be rectified (Levine and Moreland, 1998; Magee and Galinsky, 2008). The self-fulfilling nature of hierarchies means that expectations formed solely based on observable characteristics, rather than true qualities and abilities, have long-lasting, sometimes negative, consequences for teams (Bass, 1990; Bunderson, 2003; Joshi and Knight, 2015). 
Most researchers of hierarchy formation in small groups focus on socially significant diffuse status characteristics (e.g., gender, race) within domestic (e.g., North American) contexts (cf. Haas, 2005; Magee et al., 2016). To comprehend micro-level status dynamics, especially outside of these well-studied settings, status characteristics research must be supplemented with macro-level social theories (Gray and Kish-Gephart, 2013). Given our focus on multinational teams, we highlight several streams of research that inform our theorizing. One stream relevant to global stratification draws on ideas of linguistic imperialism, the dominance of English worldwide, and inequality between native and nonnative English speakers (Phillipson, 1992; 2009). Linguistic imperialism appears to trickle down because English proficiency determines individual status in teams and organizations (Neeley et al., 2012; Neeley, 2013).

Other research highlights a new global division of labor (Berberoglu, 2003; Hettne, 1995; Hoogvelt, 2001; Robinson and Harris, 2000), and although it generally treats the transnational capitalist class as homogenous, there are significant imbalances in multinational boards of directors, and the global corporate elite is essentially Euro-North American (Carroll et al., 2010). ${ }^{1}$ Micro-level implications are underexplored, but can be expected. As an example, even among global corporate elites who meet at the World Economic Forum in Davos, those from emerging markets such as Turkey, Portugal, Mexico, and South Africa are seen as second-tier participants (Graz, 2003: 331). Individuals from second-tier countries might be perceived as second-tier individuals in multinational work contexts. Preconceptions of nations falling into categories such as first/third, core/periphery, and developed/developing illustrate the stratified nature of the global societal order (Bourdieu, 2005; Go, 2008; Hettne, 1995; Hoogvelt, 2001; Meyer et al., 1997; Wallerstein, 1974). Extending status characteristics theory, we demonstrate that teams reproduce larger-scale social structures, 
including the global order. Macro-level national and linguistic power structures are reproduced at the team level because nationality and language act as status characteristics.

\section{Language as a specific status characteristic}

Research in multinational organizational settings demonstrates the effects of language, particularly English, on status and power (Hinds et al., 2013; Marschan-Piekkari et al., 1999; Neeley, 2013). When multinational teams speak English, which is almost always the case (Brannen et al., 2014; Jonsen et al., 2011), members signal leadership potential through above-average English skills. In the eye of the beholder, these skills are associated with higher status, intelligence, competence, and dependability (Behfar et al., 2006; Hinds et al., 2013; Marschan-Piekkari et al., 1999; Tenzer et al., 2013). Status characteristics theory holds that competence, however signaled, boosts one's status in teams, and language skills generally have been consistently shown to function as a signal of competence and predict leader emergence in leaderless groups across domains (Bass, 1990). English skills signal competence, even if they have little to do with it. Native English speakers are valued players in multinational team contexts, regardless of whether their language abilities are inherited and not achieved (Neeley et al., 2012; Neeley, 2013). If this phenomenon must be explained, it must be attributed partially to the dominance of English in global society: English is an expansionist, imperialistic, and hegemonic language, used by dominant groups (Phillipson, 1992; 2009). Linguistic competence (i.e., capital) carries symbolic power, so differences in linguistic competence between dominant and dominated social groups are essential to reproduction of status hierarchies during face-to-face interactions (Bourdieu, 1991; DiMaggio, 2012).

Nonetheless, English proficiency might be conceived as a specific status characteristic because it has a functional value to teams. Research points to the criticality of English as the 
lingua franca for multinational team processes; misunderstandings, lack of trust, and conflicts in these teams are often due to lack of a common language, even differences in accents and limited vocabulary (Behfar et al., 2006; Tenzer et al., 2013). Individuals with superior knowledge of the lingua franca are valued members of teams because of their expected ability to translate meaning, resolve misunderstanding, and at the very least not create it. Those who are more proficient, even among non-native speakers, are seen as more likely to move a team toward task completion because they participate more (Neeley, 2013). In newly formed, multinational teams, English proficiency is not only readily observable (i.e., known), it is also socially significant and valued because English is prominent worldwide, and functional to multinational teams. We argue that those more proficient with English are more likely to be preferred as leaders, and hence:

Hypothesis 1: English proficiency relates positively to leadership status in multinational teams.

\section{Nationality as a diffuse status characteristic}

Nationality is a strong candidate for an observable and socially significant diffuse status characteristic that is salient in multinational teams because of its accessibility and fit (Stets and Burke, 2000). First, nationality is psychologically accessible because it is an important category that differentiates between groups in the global milieu, and therefore between individuals in global settings (Reicher, 2004; Sidanius and Pratto, 1999). During transnational, face-to-face interactions, participants are often immediately explicit about their national identities during their first encounters. Second, once nationality is known, it activates national stereotypes. As an individual characteristic, it is therefore congruent with the context of multinational teams: team members expect differences between national groups, and 
ascribe (some) differences between individual peers to nationality. Local contextual cues such as the composition of teams as nationality diverse and team members' awareness of the presence of various nationalities on their team heighten the accessibility and fit of this social category. Other traits such as race and gender are important, but are secondary to nationality, which is the primary status-determining trait in multinational teams (Kirkman et al., 2013; Hambrick et al., 1998).

Although studies on status in multinational teams exist, many are bound to teams comprised of members from only two nationalities (Hinds et al., 2013; Salk and Brannen, 2000). Many others employ dichotomous categories such as native/non-native, U.S.born/non-U.S.-born and local/cosmopolitan (Castilla, 2008; Haas, 2005; Neeley, 2013), but such dichotomies fail to illuminate how leadership hierarchies are shaped in global teams that comprise several nationalities (Hinds et al., 2013). Nationality, like most other social categories, is not binary, and like most categories relevant to status, has a continuous character (Harrison and Klein, 2007). One way to think of nationality as a continuous status category is to think of development (Hettne, 1995; Hoogvelt, 2001; Ravlin and Thomas, 2005), which reflects notions of socio-cultural, in addition to economic, dominance and inequality (Meyer et al., 1997; Wallerstein, 1974). Regional levels of development have already been shown to have implications for individual status (Jost et al., 2005). National levels of development associate with disproportionate possession of positive social value, the material and symbolic things for which people strive (Sidanius and Pratto, 1999; ul Haq, 2003). Measures of (unequal) national development are tied to wealth, but also health and education (UNDP, 2009).

National development provides real or perceived privileged access to material and symbolic resources that boost individual status. Our arguments assume that members of multinational teams possess implicit knowledge about the global order that allows them to, 
perhaps unintentionally, estimate a nation's relative level of development, and thereby their partners' potential worth. They have implicit beliefs about, say, the nature of educational systems in more developed parts of the world. By extension, peers of some nationalities (are statistically more likely to) have received better education. This unintentional calculus may or may not result in a correct estimate, but such generalizations and stereotypes have palpable consequences for who is perceived as sufficiently competent to be given opportunities to lead. Relying on nationality and other diffuse cues to determine which team members are likely to be, say, more educated is imperfect but frequently necessary. Relevant experience and expertise are notoriously difficult to ascertain directly, especially when team members lack titles or roles that signal the depths of their experiences (Haas, 2005). Although we use education as an example, similar arguments apply to wealth (Bass, 1990: 71) and health (Van Vugt, 2006). National development has come to connote human capital (Sen, 2003; ul Haq, 2003), which clearly links to ideas about individuals' worth (Ashley and Empson, 2013; Becker, 2002). Although individuals from more developed nations might not be wealthier, healthier, or more educated, faced with limited information and uncertain social cues, multinational team members make these generalizations. Nationality serves as a heuristic for multinational team members to estimate peers' worth and potential contributions. Nationality and national development particularly activate preconceptions about competence and superiority_ “who's got it" as a leader in global settings, and hence:

Hypothesis 2: National development relates positively to leadership status in multinational teams.

The role of core self-evaluations 
Having outlined how multinational team members judge each other based on observable and socially significant status characteristics, we turn to the role of individual selfjudgments. Self-judgments are important because everybody participates in establishing and maintaining status hierarchies (Magee and Galinsky, 2008). A number of innate traits matter to achieving leadership status, but we are particularly interested in core self-evaluation. Core self-evaluation, or positive self-concept, is fundamental appraisals individuals make about their own self-worth and capabilities (Judge and Bono, 2001). It is a multidimensional construct comprised of emotional stability, self-esteem, locus of control, and generalized selfefficacy (Judge and Bono, 2001). These traits are (1) evaluative, going beyond merely describing oneself (e.g., "I am outgoing") to communicate self-worth (e.g., "I am a worthwhile person"); (2) fundamental, in that they encompass more specific, lower-level traits (e.g., emotional stability subsumes stress resilience); and (3) broad in scope, so they generalize beyond a single object, situation, setting, etc. (Judge and Bono, 2001; Johnson et al., 2008).

We focus on these broad, fundamental, and evaluative aspects of the self for several reasons. First, core self-evaluation links closely with modern Western, now global, conceptions of individual agency (Markus and Kitayama, 199; Meyer and Jepperson, 2000). The modern agentic individual has the capacity and responsibility to independently modify society, control nature, and feel good about herself. "Helplessness, ignorance, and passivity may be very natural human properties, but they are not the properties of the proper effective agent” (Meyer and Jepperson, 2000: 107). Thus, core self-evaluation illuminates agency within global status (re)production. Second, core self-evaluation predicts leadership status (Judge et al., 2002) because it is a valuable and valued individual quality that predicts influence in short-lived experimental settings, popularity at work and developing more social ties while abroad (Chiu et al., 2009; Scott and Judge, 2009; Zarnoth and Sniezek, 1997). Core 
self-evaluation is a source of peer evaluations, and more so than specific and diffuse status characteristics, even objective competence and performance (Chang et al., 2012). However, we are less interested in the direct effect of core self-evaluation, which we expect to be positive, and more in its capacity to shape the relationship between observable characteristics and leadership status. As a moderator, core self-evaluation might strengthen or weaken perceptions of competence based on status characteristics, and we argue that core selfevaluation interacts with specific and diffuse status characteristics differently.

When it comes to specific status characteristics such as language, the match between signals of competence and perceived self-worth is important; we expect a synergistic effect between the two. Language and core self-evaluation each boost leadership status, but combined, they have a stronger effect than a merely additive one. In theory, assigning leadership based on specific but not diffuse status characteristics offers real functional value to teams (Bunderson, 2003). Since team members strive to put the best person in charge, they pay close attention to specific status cues and use these, when available, as the foremost guiding principle in leadership assignment (Bass, 1990; Haas, 2005). Team members with a superior sense of self-worth are quick to participate actively, demonstrating their competence or lack of it. When they are active and linguistically competent, they are more successful at signaling their potential as leaders. When they are active but not competent, this is unlikely to occur and give them any specific status advantage; if anything, it disadvantages them. When they are competent but not active, they do not signal competence, and might not gain the recognition they deserve.

This synergy or enhancement argument, which holds for specific but not necessarily diffuse status characteristics, indirectly corroborates research on language that shows that when individual self-assessed and objective fluency ratings differ, job-related behavioral patterns map to individuals' own lower self-assessments (Neeley, 2013). It also parallels most 
theorizing within core self-evaluation research. Individuals with high core self-evaluations are more effective self-regulators, and are thus able to capitalize on or enhance their advantages (Judge and Hurst, 2007), so that those who deem themselves worthy are more likely to be rewarded disproportionally (Chang et al., 2012). Members of teams gain higher status when they capitalize on their linguistic advantages (i.e., when the confidence they project aligns with their salient and observable skills). Therefore:

Hypothesis 3: Core self-evaluation positively moderates the positive relationship between English proficiency and leadership status.

When it comes to diffuse status characteristics such as nationality, discrepancies with core self-evaluation are more acceptable, even advantageous in some cases. Although the interaction of core self-evaluation with observable demographics has not been explored to the extent that the one with skills has, we argue that these two interactions operate differently. For observers, personality and skill are difficult to detach (Anderson and Kilduff, 2009; Melwani et al., 2012), but personality is more easily detachable from demographics such as nationality. High core self-evaluation is particularly advantageous to those whose countries of origin are otherwise perceived to be less developed. Unlike specific status characteristics, diffuse such work insofar as they convey stereotypes that cannot be rejected. Again, this assumption relies on the notion that team members are motivated to make rational choices about their leaders, and put the best person in charge. Thus, diffuse status characteristics such as nationality, but not actual, observable skills, are given the benefit of the doubt.

A compensation argument holds for diffuse status characteristics. Since diffuse status cues are distant and less legitimate signals of competence, individuals are given room to compensate for their effects. In small groups, individual agents find it easier to compensate 
for their age, gender, race, etc. than for lack of relevant skills. Positive self-views compensate for second-rate nationality, whereas first-rate nationality compensates for lack of self-worth. Individuals with higher core self-evaluation always have higher leadership status, regardless of their competence, as signaled through language and nationality. However, the importance of exceptional development lessens by exceptional core self-evaluation, and vice-versa, so that leadership hierarchies in multinational teams reproduce the global order only for participants with low core self-evaluation. If core self-evaluation implies an agentic quality, it serves not only to reproduce and enhance extant hierarchies, but also to create change. Participants with high core self-evaluation agentically compensate for the effects of their nationality, particularly when these effects are otherwise damaging. Therefore:

Hypothesis 4: Core self-evaluation negatively moderates the positive relationship between national development and leadership status.

\section{Methods}

\section{Data and sample}

Data were collected from adults with work experience enrolled in a graduate program in business administration at an elite European business school. ${ }^{2}$ The official language of the program was English. Maximizing team diversity in terms of gender, nationality, and professional background, participants were assigned to teams in which they worked intensively for approximately four months (i.e., one semester). The program was structured such that teams were expected to meet daily to work on course preparation and team assignments that weighed substantially toward a final grade that team members received individually (between $20 \%$ and $40 \%$ ). Thus, teams were both process and outcome interdependent. Teams remained fixed for all courses during these four months so that team 
tasks, which included marketing, finance, and management, approximated the tasks of topmanagement or cross-functional project teams. Participants had no knowledge of one another prior to formation of the teams, and no leaders were assigned formally; hence, they functioned as self-managing.

The full sample consisted of 286 participants from 46 nationalities, working in 36 seven- to eight-member teams. All teams were highly diverse, with an average of 7.95 team members $(S D=0.22)$ from an average of 6.75 countries $(S D=0.77)$. National diversity was high in all teams, but invariable across teams (Blau's index $=0.82, S D=0.03$ ). Twenty-five percent of participants were female, and the average age was nearly 28 years $(S D=2.01)$. On average, participants had more than four years of professional experience $(S D=2.25)$. Data were collected using a multi-phase, multi-respondent survey instrument. Just before the formation of teams (Time 1), a web-based survey was administered to collect individual core self-evaluation to ensure there was no reciprocal effect of leadership status. Approximately four months later (Time 2), a web-based survey was administered to collect socio-metric data (i.e., individuals evaluated each other on leadership, and indicated ties of friendship and advice). This timeframe was sufficient for a conservative test of status characteristics theory (Webster, 1977; Magee and Galinsky, 2008). With the consent of participants, additional demographic and biographical information was obtained from school administration (Time 0). Responses were collected from 262 individuals at Time 1, and 263 at Time 2, yielding a response rate of approximately $92 \%$. The complete and usable sample included 230 observations. To obtain these response rates, participants were not only ensured of the confidentiality of their responses, but were also provided with individualized reports that facilitated their leadership development. 


\section{Measures}

Leadership status Leadership status $($ mean $=29.37, S D=6.51, \min =11.00, \max =45.60)$ was measured at Time 2 using relational data as the sum of attachments directed toward an actor (i.e., in-degree centrality; Sauder et al., 2012 discuss the benefits of this measure). To calculate status, an attachment was defined as a valued, unidirectional score on leadership perception. Respondents indicated on a five-item, seven-point Likert-type scale developed by Cronshaw and Lord (1987) the extent to which they perceived fellow team members as leaders. A sample item was "To what extent this individual fits your image of a leader?" $(\alpha=$ .98). Intra-class correlations of individual ratings $(\operatorname{ICC}(1)=0.07)$ and the reliability of mean ratings $(\mathrm{ICC}(\mathrm{K})=0.37)$ were adequate (LeBreton and Senter, 2008). Median $\mathrm{r}_{\mathrm{wg}}$ values (average $\left.\mathrm{r}_{\mathrm{wg}}=.90 ; M d n=.91\right)$ indicated sufficient degrees of agreement among team members when assessing target peers (James et al., 1984). In addition to the full roster method, leadership status was measured by asking individuals to nominate one team member as leader freely (mean $=0.88, S D=1.22$ ). The number of nominations received within the team correlated strongly with the centrality measure $(\rho=0.51, p<0.001)$, and thus the centrality measure was retained. Analyses with the alternative measure (available on request) accorded with primary analyses.

English proficiency Language was operationalized as a measurable and specific skill. Data collected for admissions purposes (Time 0) quantified English proficiency (mean $=0.87, \mathrm{SD}$ $=0.12, \min =0.32, \max =1.00)$. For all non-native English speakers, proficiency had to be demonstrated with an official TOEFL or TOEIC test certificate. Since these tests have different score ranges, a unified measure was obtained by scaling the scores from zero to 1 . Native English speakers were not required to take a language test, so their scores were entered as 1. English test scores in this sample were high but consistent with those in most 
international MBA programs, for which some degree of English proficiency is an entry requirement.

National development Nationality was collected at admissions and again at Time 1, at which respondents were provided with a single choice. Reports at the two points were identical. National development $($ mean $=0.81, S D=0.12, \min =0.40, \max =0.93)$ was based on the Human Development Index (HDI: UNDP, 2009). Alternative indicators of national status, including the categorical HDI measure (low to very high development), GDP per capita, and clustering along the classification of House et al. (2004), correlated highly with the measure $(\rho \geq 0.90, p<0.05)$, and yielded identical results (available on request).

Core self-evaluation Core self-evaluation $($ mean $=5.03, S D=0.72, \min =1.27, \max =6.64$ ) was measured at Time 1 using a 7-point, Likert-type scale, with a twelve-item core selfevaluation scale (Judge et al., 2003) that is validated by a growing body of evidence (Chang et al., 2012). A sample item is "I am confident I get the success I deserve in life" $(\alpha=.80)$. Although the construct consists of four broad, fundamental, and evaluative traits, the scale measures core self-evaluation itself rather than its traits, so items cut across multiple traits (e.g., "I determine what will happen in my life" overlaps with self-efficacy and locus of control).

Control variables We controlled for relevant specific and diffuse status cues. ${ }^{3}$ First, a variety of human capital indicators (i.e., specific signals of true individual quality) were collected. These were measured at Time 0 using test certificates and grade transcripts, whenever possible, to ensure controlling for true quality exogenous to one's acquired status within a team (Sauder et al., 2012). Data were collected on undergraduate grade point 
average (GPA, on a 10-point scale), total GMAT score, years of work experience, university status (Shanghai Ranking Consultancy, 2009), and language skills other than English proficiency. Language skills, which were self-reported during admissions (Time 0), included the number of languages an individual knew, and local language proficiency. These measures were repeated at Time 1 due to potential self-promotion biases at Time 0 , but no disparities were found.

We controlled for the diffuse status cues gender $(1=$ male, $0=$ female $)$, age, and marital status $(1=$ married, $0=$ single $) .{ }^{4}$ The curvilinear effect of age was non-significant, and no discrepancies were found between demographic data collected directly at Time 1 and by school administration at Time 0 . Finally, we controlled for social status acquired within the team because it relates strongly with leadership status, "so much so that the two are often confused in the literature" (Van Vugt, 2006: 357, citing Bass, 1990). Since multiple hierarchies exist within groups (Sauder et al., 2012), we isolated the confounding effect of social status and offer a robust and conservative explanation of emergent, informal leadership. We measured social status at Time 2 as the aggregate of in-degree centrality in networks of friendship and advice $(\alpha=.94)$. Respondents used seven-point Likert-type scales to mark the extent to which they "consider this team member a personal friend" (i.e., friendship) and "go to this team member for help or advice" (i.e., advice).

\section{Results}

Descriptive statistics and correlations appear in Table 1. Correlations followed expected directions. Two-level, random-effects GLS analyses with robust standard errors tested the hypotheses and accounted for the nested nature of the data. Table 2 summarizes the results. To interpret relative magnitudes of effects, standardized coefficients are included in the table. Models 1 and 2 show the relationships of leadership status with control variables. 
Results when social status was omitted (Model 1) and included (Model 2) were similar, but this additional control variable improved model fit $\left(\chi^{2}=210.44, p<0.01\right)$. Multicollinearity in Model 2 was ruled out, as all variance inflation factors (VIF) were below cut-off values of $10($ mean VIF $=1.19 ; \max$ VIF $=1.59 ;$ O’Brien, 2007). In Model 3, English proficiency and national development were added to the control variables. English proficiency did not relate to leadership status $(\beta=0.03$, n.s. $)$, and hence Hypothesis 1 was not supported. National development related positively to leadership status $(\beta=0.11, p<0.01)$, and it was among the strongest predictors of leadership in the model. Hence, Hypothesis 2 was supported. These results held after the addition of core self-evaluation (CSE; Model 4), the effect of which was positive $(\beta=0.20, p<0.01)$.

\section{INSERT TABLES $1 \& 2$ ABOUT HERE}

Model 5 tested the hypothesized moderation effects. Core self-evaluation (CSE) had a strong, positive main effect on leadership status $(\beta=0.23, p<0.01)$. Although the main effect of English proficiency was non-significant $(\beta=0.04, n . s$.$) , the interaction term English$ proficiency x CSE was positive $(\beta=0.12, p<0.05)$, supporting Hypothesis 3 and suggesting that CSE enhances specific status characteristics such as English proficiency. Simple slope analyses revealed that the effect of English proficiency was negative and marginally significant at low core self-evaluation (at -2SD: $\beta=-0.20, p<0.05$; at $-1 \mathrm{SD}: \beta=-0.08$, n.s.), but positive at high core self-evaluation (at +1SD: $\beta=0.16, p<0.05$; at +2SD: $\beta=0.28, p<$ 0.05). These crossed slopes, illustrated in the upper panel of the Figure, explain the nonsignificant main effect of English proficiency in previous models (Hypothesis 1). The main effect of national development on leadership status was non-significant in Model $5(\beta=0.06$, n.s.). As the interaction term national development x CSE demonstrates $(\beta=-0.12, p<0.05)$, core self-evaluation reversed the relationship of national development and leadership status, 
supporting Hypothesis 4 and suggesting that CSE compensates for diffuse status characteristics such as nationality. The slope of national development was significant at low core self-evaluation (at -2SD: $\beta=0.30, p<0.01$; at -1SD: $\beta=0.18, p<0.01$ ), but nonsignificant at high core self-evaluation (at +1SD: $\beta=-0.06, n . s$; at $+2 \mathrm{SD}: \beta=-0.18, n . s$ ). The lower panel of the Figure illustrates these relationships.

\section{INSERT FIGURE ABOUT HERE}

\section{Discussion}

"Very few works have looked at inequality at the global level, despite the fact that between-country inequalities have been larger than inequalities within-countries from the late 18th century," observes Riaz (2015: 1093, citing Neckerman and Torche, 2007). Calls have been made for research on global inequality within studies of work and organization, but contributions from neighboring disciplines are appearing slowly. In addition to Marx, Bourdieu provides a theoretical lens, given that symbolic, in addition to economic, capital is usually at stake (Go, 2008). For example, a recent study of individual career success in the Big 4 accounting firms suggests that a Bourdieuan conjecture of a global professional field is necessary to explain who gets to partner in these firms (Spence et al., 2015). Understanding who gets to lead multinational teams also requires interdisciplinary dialogue with grand social theories (Chudzikowski and Mayrhofer, 2011). The current study contributes to status characteristics research, which speaks mostly to the formation of small-scale interpersonal hierarchies (Berger et al., 1974; Ridgeway and Fisk, 2012). We discuss how findings relate to larger-scale (re)production of inequality in global fields (Bourdieu, 2005), and to the role of agency in this process, allowing us to draw implications for theory and practice that cut across levels of analysis. 


\section{Implications for theory}

Bourdieu-inspired field analysis begins with a sketch of what constitutes an advantage (capital) and who has it (Leander, 2010). We demonstrate that English proficiency and national development constitute an advantage within elite MBA teams. That language and nationality define member status in these teams is one indication that global elites form a field in which actors have differential command over stakes (Bourdieu, 1984; Djelic and Quack, 2010; Go, 2008). This speaks to and extends studies on transnational classes and global elites (Carroll et al., 2010; Djelic and Quack, 2010; Sklair, 2001). Elite business schools and their MBA programs fuel the transnational capitalist class (Fotaki and Prasad, 2015; Graz, 2003; Sklair, 2001), and although the class is often treated as homogenous, cosmopolitan, and unconstrained by national boundaries (Berberoglu, 2003; Hettne, 1995; Hoogvelt, 2001; Robinson and Harris, 2000), the current study suggests otherwise. Even within this global, elite class, national boundaries constrain the struggle over the symbolic value of forms of capital. In this study, rookie members of the global elite were endowed with differential amounts of linguistic and symbolic resources related to nationality, and they used these resources to gain informal leadership status. These resources differentially helped members attain the stake of stakes - the "legitimate principle of domination" (Bourdieu, 1984: 254). In originally leaderless, self-managing teams, the legitimate principle of domination is clearly informal leadership status, a form of social capital. Social capital is also at stake within organizations and labor markets, essentially defining individual career advancement (Granovetter, 1974; Sauder et al., 2012).

The concept of self-managing teams is Western, but increasingly global (Kirkman and Shapiro, 1997). Self-managing teams require one or more members to step forward and carry out leadership functions informally, which is deemed appropriate, functional, and/or legitimate because natural selection is expected to result in the most qualified member 
assuming leadership responsibilities, and the people doing the work (i.e., team members) are in the best position to judge who should take role responsibilities (cf. Bass, 1990; Paunova, 2015). Although team members do not always judge accurately who is truly qualified, they certainly esteem some individual qualities as more legitimate sources of dominance (Anderson and Brown, 2010). In self-managing, multinational teams embedded in the global field, these qualities include development, eloquence (with English), and positive selfconcept. These are all legitimate in the global field because of their Western provenance (Bourdieu, 2005; Meyer et al., 1997; Phillipson, 1992); they are all important facets of Western-style and thus global leadership (Dickson et al., 2003; Mellahi, 2000).

This study suggests that English was not as directly favored as expected. We consider the possibility that native speakers appear arrogant, or that English has become devalued in global contexts because "everyone" speaks it. However, these explanations contradict the bulk of theory (cf. Bass, 1990; Bourdieu, 1991; Neeley, 2013). That language had no immediate symbolic value is counterintuitive, but only if we fail to consider findings in total. English proficiency was valued when it was properly and agentically signaled by those with positive self-concept. Only when language conveyed average self-concepts was it irrelevant; when it conveyed negative self-concepts, it was penalized. A dubious inconsistency was unveiled when one's lack of self-worth was expressed with perfect English, which makes sense in light of theory. Status characteristics matter only when they are observable, which for English skills largely means communicated in interaction. When observing the manner in which others communicate, perceivers cannot distinguish personality and skills (Anderson and Kilduff, 2009; Melwani et al., 2012). In this context and others, personality matters more than skill (Anderson and Brown, 2010).

Overall, neither specific nor diffuse status characteristics operated automatically and inevitably to (re)produce status (dis)advantages. In getting to their status positions, 
individuals did something, or failed to. Individuals have an agentic capacity that the notion of positive self-concept (i.e., core self-evaluation) helps capture particularly well in transnational contexts, given that the Western conception of effective agents is now global (Meyer and Jepperson, 2000). This conception requires control and self-regulation-control over the self and others. Positive self-evaluation in relation to others is a critical, distinguishing feature of this modern conception of agency (Markus and Kitayama, 1991). In the current study, effective agents with positive self-concepts enhanced the symbolic value of English skills, a resource that gave them authentic and legitimate status advantages. They interfered to reduce the negative value of second-rate nationality, and they could afford to do so because nationality is a less legitimate source of status advantage (team members were not allowed to enhance the positive value of first-rate nationality).

In status characteristics research, specific and diffuse status characteristics such as language and nationality are treated as independent (Bunderson, 2003), but specific status characteristics such as academic degrees and other gains in "human capital" might result from prior status advantages in social category membership (Ashley and Empson, 2013; Bourdieu, 1984; 1986). Of particular interest is the observation that privileged and dominant groups have superior language competences and higher linguistic capital (Bourdieu, 1991; DiMaggio, 2012). The correlation between national development and English proficiency in the current sample was not trivial $(\rho=0.32, p<0.001 ; n=275)$, even when respondents from the Anglosphere-Australia, Canada, South Africa, the United Kingdom, and the United States-were excluded $(\rho=0.24, p<0.001 ; n=236)$. This was also the case for other forms of linguistic and cultural capital (e.g., local language proficiency $(\rho=0.30, \mathrm{p}<0.001)$ and to some extent university status $(\rho=0.16, \mathrm{p}<0.01)$ correlated with national development). One way to interpret these correlations is that effective agents convert their less-legitimate forms of capital (i.e., social categories they were born into such as nationality) into legitimate, 
"human capital" (i.e., cultural capital, including educational and linguistic capital). We strongly encourage future research to draw on macrosocial theories and further explore how specific and diffuse status characteristics relate (Ashley and Empson, 2013; Bourdieu, 1984; 1986).

As a part of habitus, self-image, self-control, self-esteem, etc., core self-evaluation might not be conceived in isolation from field and capital either (Bourdieu, 1984). Little research specifically examines antecedents of core self-evaluation (Johnson et al., 2008), but life circumstances influence self-views (Swann et al., 2007), and gender, race, and class share a small relationship with self-esteem and similar constructs (Kling et al., 1999; Twenge and Campbell, 2002; Twenge and Crocker, 2002). In the current study, core self-evaluation was relatively independent from English proficiency $(\rho=0.10, n . s$.$) and national development ( \rho$ $=0.15, p<0.05)$. Hysteresis, another Bourdieuan thinking tool, explains this (Leander, 2010). The self (habitus) is anchored in many fields of practice (Bourdieu, 1984), including national fields in which English and development are less significant forms of capital. Traditional national elites have high levels of core self-evaluation, the habitus that makes them evaluate their own leadership capacities positively and make leadership claims accordingly. In the global field, some of those who are successful in national fields lack the symbolic capital that makes it possible to claim the leadership roles to which they aspire legitimately. This is a case of hysteresis, a discrepancy between the habitus (i.e., core selfevaluation) and the objective conditions of agency (i.e., the possession of valued status characteristics). Hysteresis is a temporary situation in which the habitus is out of sync with the field. It is relevant primarily to new entrants in the global field because habitus is expected to adjust over time (Chudzikowski and Mayrhofer, 2011), raising several questions pertinent to practice. 


\section{Implications for practice}

What happens to elite business school graduates once they go on to work for, and manage, multinational organizations? Do their nationality and language continue to shape their careers? If so, how does that affect their self-concept? The answers depend on how multinational organizations are managed, highlighting important implications of our study for policy and practice. Within international management, there is an ongoing debate regarding the critical role of multinational organizations in promoting or resisting global convergence in dominant employment and human resource practices (Quintanilla and Ferner, 2003). The headquarter orientation of multinationals concerns individual career outcomes (Heenan and Perlmutter, 1979; Stahl and Björkman, 2006), and the management (i.e., headquarters) of some multinationals might favor developing leaders with specific national and linguistic backgrounds. In polycentric and ethnocentric organizations, local and headquarter nationals might take priority. We believe that in these organizations, the stratified global field influences individual career and leadership development less, but the global order is particularly potent in geocentric or global organizations (Heenan and Perlmutter, 1979), or organizations operating in global fields (Spence et al., 2015). The global convergence in multinationals debate is ongoing, but even the most localized functions such as human resource management appear to be converging to a global, Anglo-Saxon, U.S.-dominant, "best practices" model (Ferner and Quintanilla, 1998; Pudelko and Harzing, 2007). Some multinationals such as large professional service firms are particularly likely to operate in transnational fields in which the global (i.e., Western) dominates (Spence et al., 2015). Nearly $50 \%$ of elite business school graduates become employed in global consulting and financial services (HBS, 2015; INSEAD, 2015), suggesting that global hierarchical reproduction is likely, particularly in these sectors, but not unavoidable. Localized selection, promotion, and other human resource practices might reduce global stratification. 
Even if multinational management practices (re)produce inequality, individual organizational members might be able to avoid receiving a status discount for their nationality, and can do so particularly if their self-views are positive. Self-views are shaped by field position and access to capital in the long-run, but there is an adaptive quality to the habitus in the shorter-run too (Bourdieu 1984: 170 defines it as a "generative principle"). As part of habitus, core self-evaluation is constrained by one's history, but might also generate new practices (Chudzikowski and Mayrhofer, 2011). Actors interested in promoting diversity and equality, and individuals interested in managing their careers, could invest in development of positive self-concepts. Particularly relevant for practice, there exists psychological evidence that self-concepts can be improved. One way to do so is through training, since facets such as self-efficacy and internal locus of control increase subsequently, even among older adults (Tannenbaum et al., 1991; Wolinsky et al., 2010). Promoting development of this Western take on the self-concept might be conceived as promoting the dominant order, but alternatives might be less desirable. Current results suggest that a positive self-concept does not compensate for lack of skills but simply enhances the value of skills already in place; it does not overprivilege those born into already privileged social categories but allows individuals to compensate for life circumstances.

Finally, current findings have palpable consequences not only for justice and fairness, but also for how teams perform. Although we did not hypothesize and test this directly, extant research shows that groups perform worse (i.e., are less productive, successful, and satisfied) when leaders are selected based on demographics (i.e., diffuse status characteristics) rather than substantive indicators of competence (i.e., specific status characteristics) (Bass, 1990; Bunderson, 2003; Joshi and Knight, 2015). Managing the primacy of English proficiency, nationality, and/or self-evaluations in informal team 
leadership is important for actors who want to improve multinational team processes and outcomes.

\section{Conclusion}

This paper proposes and tests a theoretical model of how global inequalities reproduce in small groups. We are interested in the symbolic power of nationality and language to signal one's worth as leader and determine who gets to lead the multinational team. We argue that macro-level national and linguistic structures replicate at the micro level, but not inevitably. The fundamental appraisals individual agents make of their self-worth and capabilities (i.e., core self-evaluations) enhance the effects of legitimate, task-relevant status cues such as English proficiency, but compensate for the effects of less legitimate, vague status cues such as national development. This is important to practice because core selfevaluation can be trained and developed, and to theory because it shows that the perceivercentric perspective of status characteristics research can be joined with an actor-centric perspective emphasizing agency over the reproduction of structure. We update status characteristics theory to fit the new normal of multinational teams, offering robust evidence for transnational status dynamics across dozens of national categories, and reflecting critically on international management research and practice.

\section{Acknowledgments}

The author would like to thank her PhD supervisor Yih-teen Lee and her dissertation committee members for their input on early drafts of this manuscript, and for their continual support. More recent versions benefited from the insights and helpful comments of Sara Louise Muhr, Anna Leander, Dana Minbaeva, Daniel Hjort, Florence Villeseche, and Christian Poulsen, among others. The author is very grateful for the constructive feedback 
from Associate Editor John Cordery and the anonymous reviewers. Thanks also go to participants for their willingness to engage in this study.

\section{Funding}

This research received no specific grant from any funding agency in the public, commercial, or not-for-profit sectors.

\section{Notes}

${ }^{1}$ Chinese and Japanese firms, among others, are some of the world's largest corporations (Fortune Global 500; PWC Global Top 100). Yet, business elites from newly industrialized countries remain isolated from the transnational network, Japanese representation in the network has diminished, and the global elite has centered even more strongly upon Europe and North America (Carroll et al., 2010).

${ }^{2}$ In recent years, this full-time MBA program has steadily appeared on top 10 worldwide lists (The Economist, Financial Times, Forbes).

${ }^{3}$ Self-reported and country-level cultural values (i.e., collectivism, power distance, uncertainty avoidance, and masculinity) did not affect leadership status. Results are available on request.

\footnotetext{
${ }^{4}$ We conducted informal interviews with a small number of randomly selected participants ( $n$ $=6$ ) to ensure the face validity of the instrument and model. Marital status was included because participants mentioned its importance during interviews.
} 


\section{References}

Anderson C and Brown CE (2010) The functions and dysfunctions of hierarchy. Research in Organizational Behavior 30: 55-89.

Anderson C and Kilduff GJ (2009) Why do dominant personalities attain influence in face-toface groups? The competence-signaling effects of trait dominance. Journal of Personality and Social Psychology 96: 491-503.

Ashley L and Empson L (2013) Differentiation and discrimination: Understanding social class and social exclusion in leading law firms. Human Relations 66: 219-44.

Barchas PR and Fisek MH (1984) Hierarchical differentiation in newly formed groups of rhesus and humans. In: Barchas PR (ed) Essays toward a sociophysiological perspective. Westport, CT: Greenwood Press, 23-33.

Bass BM (1990) The Bass \& Stogdill's Handbook of Leadership: Theory, Research, and Managerial applications. Free Press.

Becker GS (2002) The age of human capital. In: Lazear EP (ed) Education in the TwentyFirst Century. Palo Alto: Hoover Institution Press, 3-8.

Behfar K, Kern M and Brett J (2006) Managing challenges in multicultural teams. In: Chen Y (ed) Research on Managing Groups and Teams: National Culture and Groups vol. 9. Oxford: Elsevier, 233-62.

Berberoglu B (2003) Globalization of Capital and the Nation-State: Imperialism, Class Struggle, and the State in the Age of Global Capitalism. Lanham,MD: Rowman \& Littlefield.

Berger J, Conner TL, Fisek MH (eds) (1974) Expectation States Theory: A Theoretical Research Program. Cambridge, MA: Winthrop.

Bourdieu P (1984) Distinction: A Social Critique of the Judgement of Taste. London: Routledge. 
Bourdieu P (1986) The forms of capital. In: Richardson J (ed) Handbook of Theory and Research for the Sociology of Education. New York: Greenwood, 241-58.

Bourdieu P (1991) Language and Symbolic Power. Cambridge, UK: Polity.

Bourdieu P (2005) The Social Structures of the Economy. Cambridge, UK: Polity.

Brannen MY, Piekkari R and Tietze S (2014) The multifaceted role of language in international business. Journal of International Business Studies 45: 495-507.

Bunderson JS (2003) Recognizing and utilizing expertise in work groups: A status characteristics perspective. Administrative Science Quarterly 48: 557-91.

Carroll WK, Carson C, Fennema M, Heemskerk E and Sapinski JP (2010) The Making of a Transnational Capitalist Class: Corporate Power in the 21st Century. London: Zed Books.

Castilla EJ (2008) Gender, race, and meritocracy in organizational careers. American Journal of Sociology 113: 1479-526.

Chang C-H, Ferris DL, Johnson RE, Rosen CC and Tan JA (2012) Core self-evaluations: A review and evaluation of the literature. Journal of Management 38: 81-128.

Chiu YP, Wu M, Zhuang WL and Hsu YY (2009) Influences on expatriate social networks in China. International Journal of Human Resource Management 20: 790-809.

Chudzikowski K and Mayrhofer W (2011) In search of the blue flower? Grand social theories and career research: The case of Bourdieu's theory of practice. Human Relations 64:1936.

Cohen R and Kennedy P (2013) Global Sociology (3rd edn). New York: Palgrave Macmillan. Correll SJ and Ridgeway CL (2003) Expectation states theory. In: Delamater J (ed) Handbook of Social Psychology. New York: Kluwer Academic/Plenum Publishers, 2952. 
Cronshaw SF and Lord RG (1987) Effects of categorization, attribution, and encoding processes on leadership perceptions. Journal of Applied Psychology 72: 97-106.

Della Fave LR (1980) The meek shall not inherit the earth: Self-evaluation and the legitimacy of stratification. American Sociological Review 45: 955-71.

Dickson MW, Den Hartog DN and Mitchelson JK (2003) Research on leadership in a crosscultural context: Making progress, and raising new questions. The Leadership Quarterly 14: 729-68.

DiMaggio P (2012) Sociological perspectives on the face-to-face enactment of class distinction. In: Fiske ST and Markus HR (eds) Facing social class: How societal rank influences interaction. New York: Russell Sage Foundation, 15-38.

Djelic ML and Quack S (eds) (2010) Transnational communities: Shaping global economic governance. Cambridge University Press.

Driskell JE and Mullen B (1990) Status, expectations, and behavior A meta-analytic review and test of the theory. Personality and Social Psychology Bulletin 16: 541-53.

Earley CP (1999) Playing follow the leader: Status-determining traits in relation to collective efficacy across cultures. Organizational Behavior and Human Decision Processes 80: 192-212.

Ferner A and Quintanilla J (1998) Multinationals, national business systems and HRM: The enduring influence of national identity or a process of Anglo-Saxonization? International Journal of Human Resource Management 9: 710-31.

Fotaki M and Prasad A (2015) Questioning neoliberal capitalism and economic inequality in business schools. Academy of Management Learning \& Education 14: 556-75.

Friedkin NE and Johnsen EC (2003) Attitude change, affect control, and expectation states in the formation of influence networks. Advances in Group Processes 20: 1-29. 
Go J (2008) Global fields and imperial forms: Field theory and the British and American empires. Sociological Theory 26: 201-29.

Granovetter MS (1974) Getting a Job: A Study of Contacts and Careers. Cambridge, MA: Harvard University Press.

Gray B and Kish-Gephart JJ (2013) Encountering social class differences at work: How “class work” perpetuates inequality. Academy of Management Review 38: 670-99.

Graz JC (2003) How powerful are transnational elite clubs? The social myth of the World Economic Forum. New Political Economy 8: 321-40.

Haas MR (2005) Cosmopolitans and locals: Status rivalries, deference, and knowledge in international teams. In: Mannix EA, Neale MA, Thomas-Hunt MC (eds) Research on Managing Groups and Teams: Status and Groups vol. 7. Oxford: Elsevier, 201-27.

Haas MR and Cummings JN (2014) Barriers to knowledge seeking within MNC teams: Which differences matter most? Journal of International Business Studies 46: 36-62.

Hambrick DC, Davison SC, Snell SA and Snow CC (1998) When groups consist of multiple nationalities: Towards a new understanding of the implications. Organization Studies 19.

Harrison DA and Klein KJ (2007) What the difference? Diversity constructs as separation, variety, or disparity in organizations. Academy of Management Review 32: 1199-228.

HBS (2015) Recruiting data and statistics. Available online:

http://www.hbs.edu/recruiting/data

Heenan DA and Perlmutter HV (1979) Multinational Organization Development. Reading, MA: Addison-Wesley.

Hettne B (1995) Development Theory and The Three Worlds: Towards an International Political Economy of Development (2nd edn) Harlow, UK: Adison Wesley Longman Ltd. 
Hinds PJ, Neeley TB and Cramton CD (2013) Language as a lightning rod: Power contests, emotion regulation, and subgroup dynamics in global teams. Journal of International Business Studies 45: 536-61.

Hoogvelt A (2001) Globalization and the Postcolonial World: The New Political Economy of Development (2nd edn) London, UK: Pelgrave.

House RJ, Hanges PJ, Javidan M, Dorfman PW, Gupta V (eds) (2004) Culture, Leadership, and Organizations: The GLOBE Study of 62 Societies. Thousand Oaks, CA: Sage.

INSEAD (2015) Employment statistics: MBA graduates 2014-2015. Available online: http://mba.insead.edu/documents/mba_employment_statistics.pdf

James LR, Demaree RG and Wolf G (1984) Estimating within-group interrater reliability with and without response bias. Journal of Applied Psychology 69: 85-98.

Johnson RE, Rosen CC and Levy PE (2008) Getting to the core of core self-evaluation: a review and recommendations. Journal of Organizational Behavior 29: 391-413.

Jonsen K, Maznevski ML and Schneider SC (2011) Diversity and its not so diverse literature: An international perspective. International Journal of Cross-Cultural Management 11: $35-62$

Joshi A and Knight AP (2015) Who defers to whom and why? Dual pathways linking demographic differences and dyadic deference to team effectiveness. Academy of Management Journal 58: 59-84.

Jost JT, Kivetz Y, Rubini M, Guermandi G and Mosso C (2005) System-justifying functions of complementary regional and ethnic stereotypes: Cross-national evidence. Social Justice Research 18: 305-33.

Judge TA and Bono JE (2001) Relationship of core self-evaluations traits—self-esteem, generalized self-efficacy, locus of control, and emotional stability-with job satisfaction and job performance: A meta-analysis. Journal of Applied Psychology 86: 80-92. 
Judge TA and Hurst C (2007) Capitalizing on one's advantages: role of core selfevaluations. Journal of Applied Psychology 92: 1212-27.

Judge TA, Bono JE, Ilies R and Gerhardt M (2002) Personality and leadership: A qualitative and quantitative review. Journal of Applied Psychology 87: 765-80.

Judge TA, Erez A, Bono JE and Thoresen CJ (2003) The core self-evaluations scale:

Development of a measure. Personnel Psychology 56: 303-31.

Kirkman BL and Shapiro DL (1997) The impact of cultural values on employee resistance to teams: Toward a model of globalized self-managing work team effectiveness. Academy of Management Review 22: 730-57.

Kirkman BL, Cordery JL, Mathieu J, Rosen B and Kukenberger M (2013) Global organizational communities of practice: The effects of nationality diversity, psychological safety, and media richness on community performance. Human Relations 66: 333-62.

Kling KC, Hyde JS, Showers CJ and Buswell BN (1999) Gender differences in self-esteem: a meta-analysis. Psychological Bulletin 125: 470-500.

Leander A (2010) Habitus and field. The International Studies Encyclopedia 5: 3255-70.

LeBreton JM and Senter JL (2008) Answers to 20 questions about interrater reliability and interrater agreement. Organizational Research Methods 11: 815-52.

Levine JM and Moreland RL (1998) Small groups. In: Lindzey G, Gilbert D and Fiske ST (eds) The Handbook of Social Psychology, 2. Oxford: Oxford University Press, 415-69. Magee JC and Galinsky AD (2008) Social hierarchy: The self-reinforcing nature of power and status. Academy of Management Annals 2: 351-98.

Magee JC, Rucker DD and Galinsky AD (2016) An agentic-communal model of inequality: How the psychology of advantage and disadvantage integrates research on social class, gender, race, and power. Paper presented at the European Group for Organizational Studies, Naples. 
Markus HR and Kitayama S (1991) Culture and the self: Implications for cognition, emotion, and motivation. Psychological Review 98: 224-53.

Marschan-Piekkari R, Welch D and Welch L (1999) In the shadow: The impact of language on structure, power and communication in the multinational. International Business Review 8: 421-40.

Mellahi K (2000) The teaching of leadership on UK MBA programmes: A critical analysis from an international perspective. Journal of Management Development 19: 297-308.

Melwani S, Mueller JS and Overbeck JR (2012) Looking down: The influence of contempt and compassion on emergent leadership categorizations. Journal of Applied Psychology 97: 1171-85.

Meyer JW and Jepperson RL (2000). The 'actors' of modern society: The cultural construction of social agency. Sociological Theory 18: 100-20.

Meyer JW, Boli J, Thomas GM and Ramirez FO (1997) World society and the nationstate. American Journal of Sociology 103: 144-81.

Neckerman KM and Torche F (2007) Inequality: Causes and consequences. Annual Review of Sociology 33: 335-57.

Neeley TB (2013) Language matters: Status loss and achieved status distinctions in global organizations. Organization Science 24: 476-97.

Neeley TB, Hinds PJ and Cramton CD (2012) The (un)hidden turmoil of language in global collaboration. Organizational Dynamics 41: 236-44.

O'Brien RM (2007) A caution regarding rules of thumb for variance inflation factors. Quality \& Quantity 41: 673-90.

Paunova M (2015) The emergence of individual and collective leadership in task groups: A matter of achievement and ascription. The Leadership Quarterly 26: 935-57.

Phillipson R (1992) Linguistic Imperialism. Oxford: Oxford University Press. 
Phillipson R (2009) Linguistic Imperialism Continued. New York: Routledge.

Pudelko M and Harzing AW (2007) Country-of-origin, localization, or dominance effect? An empirical investigation of HRM practices in foreign subsidiaries. Human Resource Management 46: 535-59.

Quintanilla J and Ferner A (2003) Multinationals and human resource management: Between global convergence and national identity. International Journal of Human Resource Management 14: 363-68.

Ravlin EC and Thomas DC (2005) Status and stratification processes in organizational life. Journal of Management 31: 966-87.

Reicher S (2004) The context of social identity: Domination, resistance, and change. Political Psychology 25: 921-45.

Riaz S (2015) Bringing inequality back in: The economic inequality footprint of management and organizational practices. Human Relations 68: 1085-97.

Ridgeway CL (2001) Gender, status, and leadership. Journal of Social Issues 57: 637-55.

Ridgeway CL (2004) Status characteristics and leadership In: Van Knippenberg D and Hogg MA (eds) Leadership \& Power: Identity Processes in Groups \& Organizations. London: Sage, 65-78.

Ridgeway CL and Fisk SR (2012) Class rules, status dynamics, and 'gateaway' interactions. In: Fiske ST and Markus HR (eds) Facing social class: How societal rank influences interaction. New York: Russell Sage Foundation, 131-51.

Robinson WI and Harris J (2000) Towards a global ruling class? Globalization and the transnational capitalist class. Science \& Society 64: 11-54.

Roediger DR (2002) Colored White: Transcending the Racial Past. Berkeley: UC Press. Salk JE and Brannen MY (2000) National culture, networks and individual influence in a multinational management team. Academy of Management Journal 43: 191-202. 
Sauder M, Lynn F and Podolny JM (2012) Status: Insights from organizational sociology. Annual Review of Sociology 38: 267-83.

Scott BA and Judge TA (2009) The popularity contest at work: who wins, why, and what do they receive? Journal of Applied Psychology 94: 20-33.

Sen A (2003) Human capital and human capability. In: Fukuda-Parr S and Kumar AKS (eds) Readings in Human Development. Oxford: Oxford University Press, 35-37.

Shanghai Ranking Consultancy (2009) Academic Ranking of World Universities. Available online: http://www.shanghairanking.com/ARWU2009.html

Sidanius J and Pratto F (1999) Social Dominance: An Intergroup Theory of Social Hierarchy and Oppression. New York: Cambridge University Press.

Sidanius J, Pratto F, Van Laar C and Levin S (2004) Social dominance theory: Its agenda and method. Political Psychology 25: 845-80.

Sklair L (2001) The Transnational Capitalist Class. Oxford: Blackwell.

Spence C, Dambrin C, Carter C, Husillos J and Archel P (2015) Global ends, local means: Cross-national homogeneity in professional service firms. Human Relations 68: 765-88.

Stahl GK and Björkman I (eds) (2006) Handbook of Research in International Human Resource Management. Cheltenham, UK: Edward Edgar Publishing.

Stets JE and Burke PJ (2000) Identity theory and social identity theory. Social Psychology Quarterly 63: 224-37.

Swann WB, Jr., Chang-Schneider C and McClarty LK (2007) Do people's self-views matter? Self-concept and self-esteem in everyday life. American Psychologist 62: 84-94.

Tannenbaum SI, Mathieu JE, Salas E and Cannon-Bowers JA (1991) Meeting trainees' expectations: The influence of training fulfillment on the development of commitment, self-efficacy, and motivation. Journal of Applied Psychology 76: 759-69.

Tenzer H, Pudelko M and Harzing AW (2013) The impact of language barriers on trust 
formation in multinational teams. Journal of International Business Studies 45: 508-35.

Twenge JM and Campbell WK (2002) Self-esteem and socioeconomic status: A metaanalytic review. Personality and Social Psychology Review 6: 59-71.

Twenge JM and Crocker J (2002) Race and self-esteem: Meta-analyses comparing Whites, Blacks, Hispanics, Asians, and American Indians. Psychological Bulletin 128: 371-408. ul Haq M (2003) The human development paradigm. In: Fukuda-Parr S and Kumar AKS (eds) Readings in Human Development. Oxford: Oxford University Press, 17-34.

UNDP (2009) Human Development Report. New York: Palgrave Macmillan.

Van Vugt M (2006) Evolutionary origins of leadership and followership. Personality and Social Psychology Review 10: 354-71.

Wallerstein I (1974) The rise and future demise of the world capitalist system: Concepts for comparative analysis. Comparative Studies in Society and History 16: 387-415.

Webster M, Jr (1977) Equating characteristics and social interaction. Sociometry 40: 41-50. Wolinsky FD, Vander Weg MW, Martin R, Unverzagt FW, WillisMarsiske SL ... Tennstedt M (2010) Does cognitive training improve internal locus of control among older adults? The Journals of Gerontology: Social Science 65: 591-98.

Zarnoth P and Sniezek JA (1997) The social influence of confidence in group decision making. Journal of Experimental Social Psychology 33: 345-66. 
Table 1. Summary statistics and correlations ${ }^{\mathrm{a}}$

\begin{tabular}{|c|c|c|c|c|c|c|c|c|c|c|c|c|c|c|c|c|}
\hline & & Mean & $S D$ & 1 & 2 & 3 & 4 & 5 & 6 & 7 & 8 & 9 & 10 & 11 & 12 & 13 \\
\hline 1 & Leadership status & 29.37 & 6.51 & & & & & & & & & & & & & \\
\hline 2 & Age & 27.72 & 1.97 & 0.05 & & & & & & & & & & & & \\
\hline 3 & Gender $(1=$ male $)$ & 0.75 & 0.43 & $0.19^{*}$ & $0.18^{*}$ & & & & & & & & & & & \\
\hline 4 & Married (1 = yes) & 0.14 & 0.35 & 0.06 & $0.14^{*}$ & 0.09 & & & & & & & & & & \\
\hline 5 & Years of work experience & 4.25 & 2.25 & 0.02 & $0.56^{*}$ & 0.02 & $0.14^{*}$ & & & & & & & & & \\
\hline 6 & Undergraduate GPA & 7.62 & 0.97 & $0.12 *$ & 0.00 & -0.06 & 0.02 & 0.04 & & & & & & & & \\
\hline 7 & GMAT score & 659.61 & 46.10 & 0.00 & $-0.13^{*}$ & 0.09 & -0.07 & -0.10 & 0.08 & & & & & & & \\
\hline 8 & University status & 141.65 & 188.32 & 0.07 & 0.11 & 0.00 & -0.04 & 0.02 & -0.01 & 0.06 & & & & & & \\
\hline 9 & Number of languages & 2.58 & 0.92 & 0.07 & -0.06 & -0.04 & -0.05 & -0.04 & -0.07 & -0.12 & $-0.14^{*}$ & & & & & \\
\hline 10 & Local language proficiency & 2.71 & 2.07 & $0.24^{*}$ & -0.07 & 0.00 & 0.11 & -0.10 & -0.10 & $-0.20^{*}$ & $-0.17^{*}$ & $0.28^{*}$ & & & & \\
\hline 11 & Social status & 35.08 & 6.91 & $0.81^{*}$ & 0.04 & $0.17^{*}$ & 0.00 & 0.04 & 0.07 & -0.08 & -0.02 & 0.07 & $0.23^{*}$ & & & \\
\hline 12 & English proficiency & 0.87 & 0.12 & $0.19^{*}$ & 0.04 & 0.02 & -0.08 & 0.07 & 0.07 & $0.31^{*}$ & 0.06 & -0.06 & 0.11 & 0.11 & & \\
\hline 13 & National development & 0.81 & 0.12 & $0.22^{*}$ & $0.30^{*}$ & 0.09 & 0.01 & $0.16^{*}$ & 0.02 & $-0.17^{*}$ & $0.16^{*}$ & 0.03 & $0.30^{*}$ & 0.11 & $0.32^{*}$ & \\
\hline 14 & Core self-evaluation & 5.03 & 0.72 & $0.38^{*}$ & -0.07 & $0.12^{*}$ & 0.00 & 0.02 & 0.03 & 0.05 & 0.00 & 0.06 & $0.25^{*}$ & $0.22^{*}$ & 0.10 & $0.15^{*}$ \\
\hline
\end{tabular}

${ }^{a} n=245-286$ (pairwise). $\mathrm{SD}=$ standard deviation; GPA = grade point average; GMAT = Graduate Management Admission Test. ${ }^{*} p<0.05$ 
Table 2. Results of two-level random-effects generalized least squares ${ }^{\mathrm{a}}$

\begin{tabular}{|c|c|c|c|c|c|}
\hline & $\begin{array}{c}\text { Model 1 } \\
\beta \text { (Robust SE) } \\
\end{array}$ & $\begin{array}{c}\text { Model 2 } \\
\beta \text { (Robust SE) } \\
\end{array}$ & $\begin{array}{c}\text { Model 3 } \\
\beta \text { (Robust SE) } \\
\end{array}$ & $\begin{array}{c}\text { Model } 4 \\
\beta \text { (Robust SE) } \\
\end{array}$ & $\begin{array}{c}\text { Model 5 } \\
\beta \text { (Robust SE) } \\
\end{array}$ \\
\hline \multicolumn{6}{|l|}{$\begin{array}{l}\text { Regression coefficients } \\
\text { (fixed effects) }\end{array}$} \\
\hline Age & $0.03(.06)$ & $-0.01 \quad(.04)$ & $-0.05(.05)$ & $-0.03(.04)$ & $-0.04(.04)$ \\
\hline Gender $(1=$ male $)$ & $0.15(.06)^{* *}$ & $0.05 \quad(.04)$ & $0.04 \quad(.03)$ & $0.03(.04)$ & $0.03 \quad(.04)$ \\
\hline Married ( $1=$ yes $)$ & $0.02(.06)$ & $0.04 \quad(.03)$ & $0.05(.03)^{\dagger}$ & $0.05(.02)^{*}$ & $0.05(.03)^{\dagger}$ \\
\hline Years of work experience & $0.00 \quad(.07)$ & $0.01 \quad(.05)$ & $0.01 \quad(.05)$ & $-0.01 \quad(.05)$ & $-0.01 \quad(.04)$ \\
\hline Undergraduate GPA & $0.12(.04)^{* *}$ & $0.07(.03)^{*}$ & $0.07(.03)^{*}$ & $0.06(.03)^{\dagger}$ & $0.05 \quad(.03)$ \\
\hline GMAT score & $0.03(.05)$ & $0.08(.03)^{*}$ & $0.07(.04)^{\dagger}$ & $0.05(.03)$ & $0.05 \quad(.03)$ \\
\hline University status & $0.10(.05)^{*}$ & $0.10(.04)^{* *}$ & $0.09(.04)^{*}$ & $0.09(.04)^{*}$ & $0.08(.04)^{*}$ \\
\hline Number of languages & $0.06(.05)$ & $0.06(.03)^{\dagger}$ & $0.07(.03)^{\dagger}$ & $0.08(.03)^{*}$ & $0.08(.03)^{*}$ \\
\hline Local language proficiency & $0.22(.07)^{* *}$ & $0.07(.04)^{\dagger}$ & $0.03(.04)$ & $0.00 \quad(.04)$ & $0.01 \quad(.04)$ \\
\hline Social status & & $0.79(.04)^{* *}$ & $0.79(.04)^{* *}$ & $0.77(.04)^{* *}$ & $0.78(.04)^{* *}$ \\
\hline English proficiency & & & $0.03(.05)$ & $0.04(.05)$ & $0.04 \quad(.05)$ \\
\hline National development & & & $0.11(.04)^{* *}$ & $0.09(.04)^{*}$ & $0.06(.04)$ \\
\hline Core self-evaluation (CSE) & & & & $0.20(.05)^{* * *}$ & $0.23(.05)^{* *}$ \\
\hline English proficiency $\times$ CSE & & & & & $0.12(.05)^{*}$ \\
\hline National development $\times$ CSE & & & & & $-0.12(.05)^{*}$ \\
\hline Intercept & $0.03(.10)$ & $0.01 \quad(.04)$ & $0.01 \quad(.04)$ & $0.02(.04)$ & $0.03 \quad(.04)$ \\
\hline \multicolumn{6}{|l|}{$\begin{array}{l}\text { Variance components } \\
\text { (Random effects) }\end{array}$} \\
\hline Intercept $\left(\tau_{00}\right)$ & 0.52 & 0.10 & 0.15 & 0.19 & 0.22 \\
\hline Residual $\left(\sigma^{2}\right)$ & 0.78 & 0.56 & 0.55 & 0.52 & 0.50 \\
\hline Intraclass correlation $(\rho)$ & 0.31 & 0.03 & 0.07 & 0.12 & 0.16 \\
\hline$R^{2}$ within & 0.13 & 0.56 & 0.57 & 0.63 & 0.65 \\
\hline$R^{2}$ between & 0.15 & 0.87 & 0.87 & 0.86 & 0.85 \\
\hline$R^{2}$ overall & 0.12 & 0.67 & 0.68 & 0.72 & 0.73 \\
\hline
\end{tabular}

${ }^{a} n=250$ (Models 1 and 2), $n=247$ (Model 3), $n=230$ (Models 4 and 5). SE = standard error; GPA = grade point average; GMAT $=$ Graduate Management Admission Test.

${ }^{\dagger} p<0.10 \quad{ }^{*} p<0.05 \quad{ }^{* *} p<0.01$ 


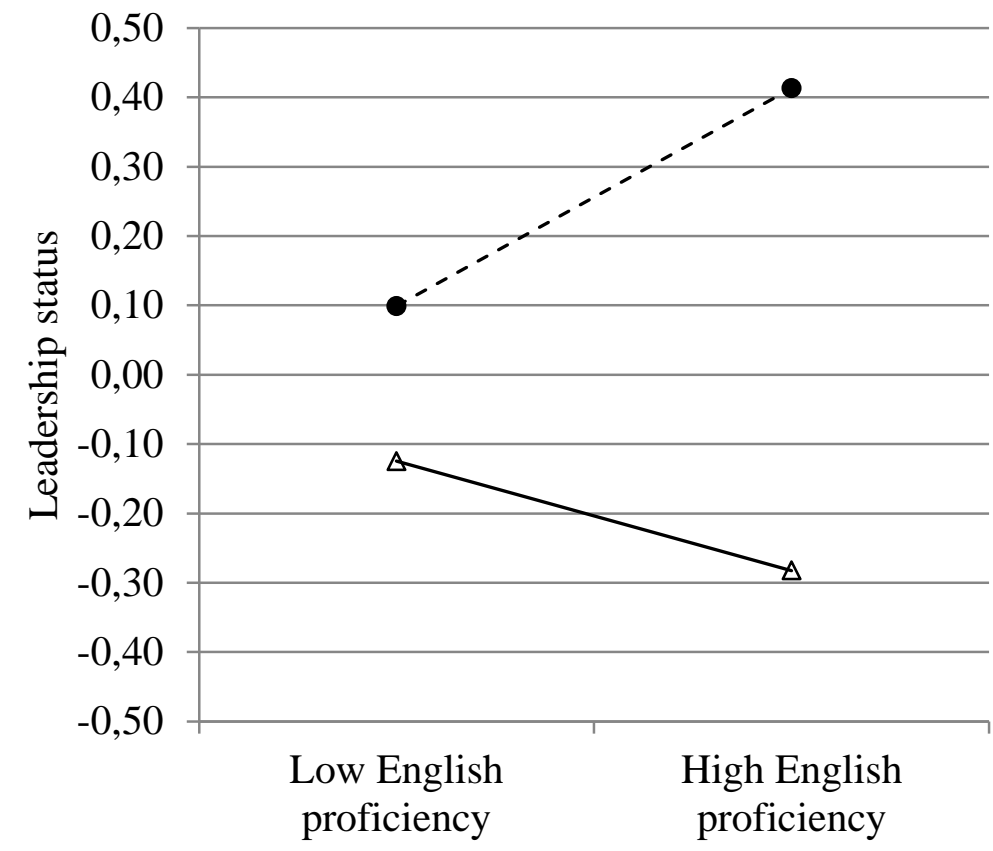

$\triangle$ Low core self-evaluation

$-\rightarrow$ - High core self-evaluation

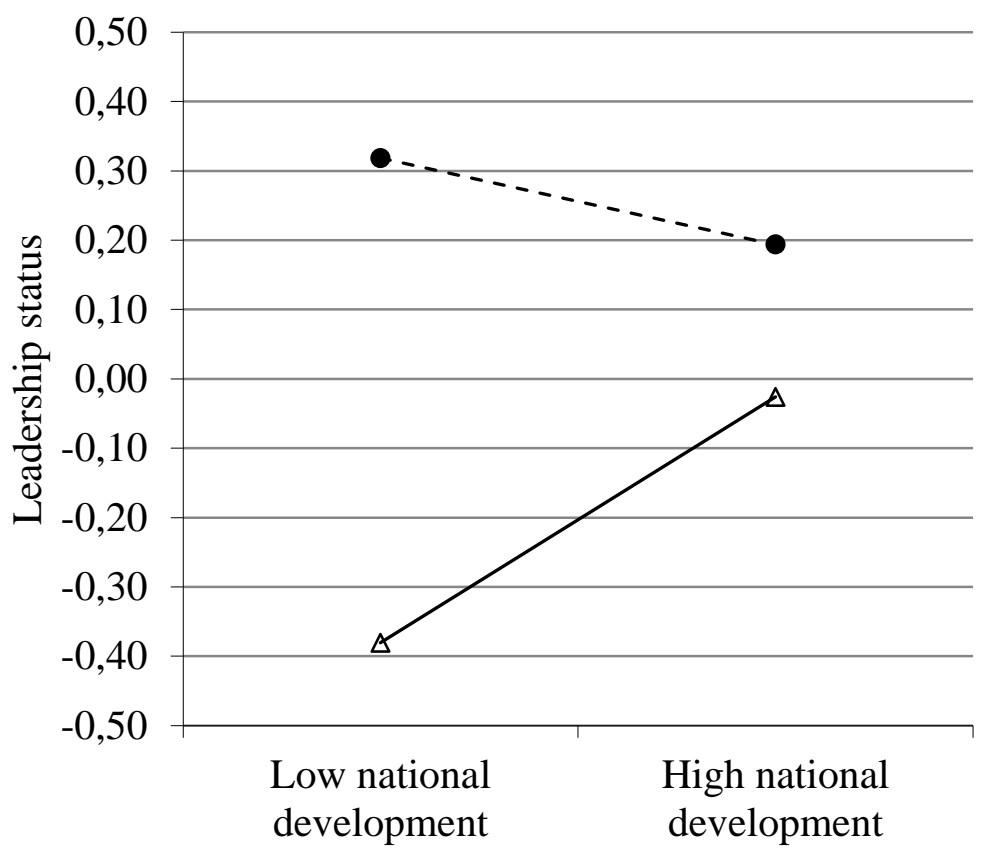

$\triangle$ Low core self-evaluation

$-\rightarrow$ - High core self-evaluation

Note: Effects are plotted at one standard deviation below the mean (low) and one standard deviation above the mean (high).

Figure 1. The moderating role of core self-evaluation. 